\section{СТАТИСТИКА, ЕСЕП ЖӘНЕ АУДИТ}

\section{СТАТИСТИКА, УЧЕТ И АУДИТ}

\section{STATISTICS, ACCOUNT AND AUDIT}

ISSN 1563-2415

Ежеквартальный научнопрактический журнал издается с 1999 года.

№ 1(84) 2022

Учредитель «Алматинский гуманитарно-экономический университет»

Алматинский гуманитарно-экономический университет

Главный редактор

Досаева С.К.

Заместители гл. редактора:

Корвяков В.А. - д.п.н., проф., ректор АГЭУ

Сейтхамзина Г.Ж. - к.э.н., проф., проректор по науке и инновациям АГЭУ

\section{Члены редколлегии:}

Амирханова Г.А. - доктор $\mathrm{PhD}$, снс ИИВТ КН МОН РК, г.Нур-Султан, Казахстан

Бекенова Л.М. - к.э.Н., профессор, проректор по академической работе АГЭУ

Дауренбеков А.К. - к.э.н., проф. АГЭУ, г. Алматы, Казахстан

Дырка Стефан - д.э.н., проф., Верхнесилезский экономический Университет имени Вой- цеха Корфанти в Катовицах, Польша

Ерж⿻анов М.С. - д.э.н., проф., партнер «Grant Thornton», г.Алматы, Казахстан

Ешпанова Д.Д. - к.э.н., доцент кафедры "Учет, аудит и статистика" АГЭУ, г.Алматы, Казахстан

Макыш С.Б. - д.э.н., проф., декан экономического факультета, ЕНУ им.Л.Н.Гумилева, г.Нур-Султан, Казахстан

Мезенцева T.M. - д.э.н., профессор департамента учета, анализа и аудита Финансового Университета при правительстве РФ, г.Москва, Россия

Назарова В.Л. - Д.э.н., проф., зав. кафедрой "Учет, аудит и статистика" АГЭУ, г.Алматы, Казахстан

Рахметова P.У. - д.э.н, проф., Туран - Астана, Нурсултан, Казахстан

Сейдахметова Ф.С. - д.э.н., проф. кафедры "Учет, аудит и статистика" АГЭУ, г.Алматы, Казахстан

Taunoв T.A. - к.э.н., проф., АГЭУ, г.Алматы, Казахстан

Тайгашинова К.T. - д.э.Н., проф кафедры "Учет, аудит и статистика", АГЭУ, г.Алматы, Казахстан

Шокаманов Ю.К. - Д.э.н., проф., г.Нур-Султан, Казахстан

\section{Издательский центр}

Алматинского гуманитарно-

экономического университета

050035, г.Алматы,

ул.Жандосова, 59,

тел: +7 7273095820 ,

$+77273095815$

факс: + 77273093000

e-mail: zhurnal.aesa.99@mail.ru

www.journal.ageu.kz, www.ageu.kz

Ответственный за выпуск журнала Айтжанова Н.M.

Подписано в печать: 26.01.2022г.

Формат 70x108 1/16.

Бумага офсетная.

Тираж 300 экз.

\section{ИП «Аруна»}

г.Алматы, Алмалинский район, ул. Нурмакова, 26/195 кв. 49 e-mail: mail: iparuna@yandex.ru 
ISSN 1563-2415

Учреждение «Алматинский гуманитарно-экономический университет», 050035, г. Алматы, ул. Жандосова, 59, тел.(727) 309-58-20, 309-58-15, вн. 138 e-mail: zhurnal.aesa.99@mail.ru, aesa2005@mail.ru

Website: journal.ageu.kz, www.ageu.kz

Регистрационное свидетельство № 9099-Ж от 25.03.2008 г. выдано Министерством культуры и информации Республики Казахстан, Комитетом информации и архивов

Журнал включен в Российский индекс научного цитирования (РИНЦ) и размещается в научной электронной библиотеке (WWW.ELIBRARY.RU) (Лицензионный договор с ООО «НЭБ» № 133-03/2016 г.Москва 11 марта 2016 г.). 
Раман Ибрахим, Сюзана Бахарудин

МЕЛИМАУ ПОЛИТЕХНИКАЛЫҚ ИНСТИТУТЫНДА КОВИД-19

ПАНДЕМИЯСЫ КЕЗІНДЕ СИНХРОНДАЛҒАН ОНЛАЙН ОҚЫТУҒА

КЕНЕТ ӨТУ: ИНЖЕНЕРЛІК ФАКУЛЬТЕТІ СТУДЕНТТЕРІ

ПЕРСПЕКТИВАСЫН САНДЫК ЗЕРТТЕУ ...

Нориымах Осман

4IR ЭЛЕМЕНТТЕРІН ҚОЛДАНУ АРҚЫЛЫ ТЖКБ ЦИФРЛАНДЫРУ.

Тан Си Мин

ЦИФРЛІК МІНЕЗ-ҚҰЛЫҚТЫ ДАМЫТУ ЖӘНЕ МУЛЬТИФИКАЦИЯ МЕН ИННОВАЦИЯЛЫҚ ОҚЫТУ ҚҰРАЛЫ РЕТІНДЕ ИНТЕГРАЦИЯЛАУ:

ОҚУДАҒЫ СТУДЕНТТЕРДІН МІНЕЗ-ҚҰЛҚЫНА ӘСЕРІ.

\section{Тео Пей Киан}

ӨНДІРІСТІК СТУДЕНТТЕРДІ ОҚУ ТИІМДІЛІГІНЕ ОҚУ

ИННОВАЦИЯЛАРЫНЫҢ ӘСЕРІ ЖОҒАРЫ ОҚУ ОҚУЫНДАҒЫ

ДИЗАЙН.....

Дви Вахюнинсси, Сламет Утомо, Шри Сурачми, Сажида Досаева

КОВИД-19 ПАНДЕМИЯСЫ КЕЗІНДЕ ОНЛАЙН ОҚЫТУДЫН САПАСЫН

АРТТЫРУДАҒЫ КӨШБАСШЫНЫН РӨЛІ.

А.Адельбаева, А. Бекметова

АЗЫҚ-ТҮЛІКПЕН МОЛЫҚТЫРУДЫ ҚАМТАМАСЫЗ ЕТУ ҮШІН

АГРАРЛЫҚ НАРЫҚТЫ РЕТТЕУ.

А. Джумабаева, Д. Бабаш, А.Кенджасарова, Р.Арзикулова

ҚАЗАҚСТАННЫН АЗЫҚ-ТҮЛІК ҚАУІПСІЗДІГІН ҚАМТАМАСЫЗ ЕТУ:

ТЕОРИЯ, ӘДІСТЕМЕ ЖӘНЕ ПРАКТИКА

А. Нуртаева, С. Айткулова, А.Садвакасова, А.Кұрмантаева

КОММЕРЦИЯЛЫҚ БАНКТЕРДЕГІ ТӘУЕКЕЛДЕРДІ БАСҚАРУ ЖҮЙ-

ЕСІНІН ТИІМДІЛІГІН ТАЛДАУ.

\section{А.Рамазанов, С.Базылхан}

ҚОНАҚЖАЙЛЫЛЫҚТЫН КОНЦЕПТУАЛДЫҚ НЕГІЗДЕРІ.

А.Рамазанов, Ж.Куралов

ҚОНАҚ ҮЙ ІСІНІҢ ЭКОНОМИКАЛЫҚ СИПАТТАМАСЫ.

II.A. Topzaeвa

КОМПАНИЯ ҚЫЗМЕТІНДЕГІ ИНТЕРНЕТ МАРКЕТИНГ 


\section{СОДЕРЖАНИЕ}

Раман Ибрагим, Сюзана Бахарудин

ВНЕЗАПНЫЙ ПЕРЕХОД К СИНХРОНИЗИРОВАННОМУ ОНЛАЙНОБУЧЕНИЮ ВО ВРЕМЯ ПАНДЕМИИ COVID-19 В ПОЛИТЕХНИЧЕСКОМ ИНСТИТУТЕ МЕРЛИМАУ: КОЛИЧЕСТВЕННОЕ ИССЛЕДОВАНИЕ ПЕРСПЕКТИВ СТУДЕНТОВ ФАКУЛЬТЕТА МАШИНОСТРОЕНИЯ.............. 6

Норшыммах Осман

ОЦИФРОВКА ТVЕТ С ИСПОЛЬЗОВАНИЕМ ЭЛЕМЕНТОВ 4IR.

Тан Си Мин

РАЗРАБОТКА ЦИФРОВОГО ПОВЕДЕНИЯ И ИНТЕГРИРОВАНИЕ С МУЛЬТИФИКАЦИЕЙ В КАЧЕСТВЕ ИННОВАЦИОННОГО УЧЕБНОГО СРЕДСТВА: ВЛИЯНИЕ НА ПОВЕДЕНИЕ УЧАЩИХСЯ В ОБУЧЕНИИ.......

\section{Тео Пей Киан}

ВЛИЯНИЕ ОБУЧАЮЩИХ ИННОВАЦИЙ НА ЭФФЕКТИВНОСТЬ ОБУЧЕНИЯ СТУ ДЕНТОВ ПРОМЫШЛЕННЫХ ДИЗАЙН В ВЫСШЕМ ОБРАЗО-

ВАНИИ.

Dwi Wahyuningsih, Slamet Utomo, Sri Surachmi, Сажида Досаева

РОЛЬ РУКОВОДИТЕЛЯ В ПОВЫШЕНИИ КАЧЕСТВА ОНЛАЙН-

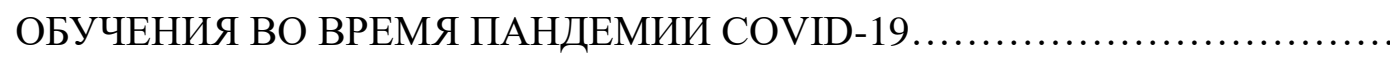

А.Адельбаева, А.Бекметова

РЕГУЛИРОВАНИЕ АГРАРНОГО РЫНКА ДЛЯ ОБЕСПЕЧЕНИЯ ПРОДО-

ВОЛЬСТВЕННОГО НАСЫЩЕНИЯ.

А. Джумабаева, Д. Бабаш, А.Кенджасарова, Р. Арзикулова ОБЕСПЕЧЕНИЕ ПРОДОВОЛЬСТВЕННОЙ БЕЗОПАСНОСТИ КАЗАХСТАНА: ТЕОРИЯ, МЕТОДОЛОГИЯ И ПРАКТИКА.

А. Нуртаева, С. Айткулова, А.Садвакасова А. Құрмантаева

АНАЛИЗ ЭФФЕКТИВНОСТИ СИСТЕМЫ УПРАВЛЕНИЯ РИСКАМИ В КОММЕРЧЕСКИХ БАНКАХ

\section{Рамазанов А., С.Базылхан}

КОНЦЕПТУАЛЬНЫЕ ОСНОВЫ ГОСТЕПРИИМСТВА.

Рамазанов А., Ж.Куралов

ЭКОНОМИЧЕСКИЕ ХАРАКТИРИСТИКИ ГОСТИНИЧНОГО ДЕЛА.

U.A Торгаева

ИНТЕРНЕТ - МАРКЕТИНГ В КОМПАНИЯХ 


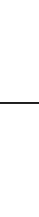

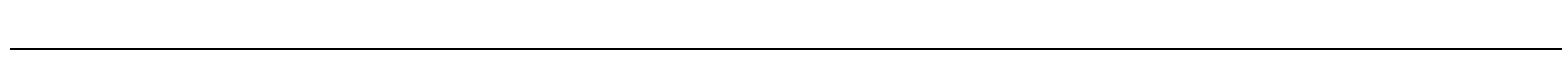

\section{Raman Ibrahim, Suzana Baharudin}

THE SUDDEN TRANSITION TO SYNCHRONIZED ONLINE LEARNING DURING THE COVID-19 PANDEMIC IN POLITEKNIK MERLIMAU: A QUANTITATIVE STUDY EXPLORING MECHANICAL ENGINEERING STUDENT'S PERSPECTIVES.

Norshymah Osman

DIGITALIZING TVET USING 4IR ELEMENTS.

Tan Si Min

DEVELOP DIGITAL STORYTELLING INTEGRATES WITH ANIMATION AS AN INNOVATIVE INSTRUCTIONAL TOOL: EFFECTS ON STUDENT'S BEHAVIOURAL ENGAGEMENT IN LEARNING.

Teo Pei Kian

THE EFFECT OF TEACHING INNOVATION ON LEARNING EFFECTIVENESS AMONG THE STUDENTS OF INDUSTRIAL

DESIGN IN HIGHER EDUCATION

Dwi Wahyuningsih, Slamet Utomo, Sri Surachmi, Sazhida Dossayeva

THE ROLE OF THE PRINCIPAL IN IMPROVING THE QUALITY OF ONLINE LEARNING DURING THE COVID-19 PANDEMIC

A. Adelbaeva Phd student, A. Bekmetova

REGULATION OF THE AGRICULTURAL MARKET TO ENSURE FOOD SATURATION

A. Dzhumabayeva, D. Babash, A. Kendzhasarova, R.Arzikulova

ENSURING FOOD SECURITY IN KAZAKHSTAN: THEORY, METHODOLOGY AND PRACTICE.

A. Nurtayeva, S. Aitkulova, A.Sadvakassova, A. Kurmantaeva

ANALYSIS OF THE EFFECTIVENESS OF THE RISK MANAGEMENT SYSTEM IN COMMERCIAL BANKS

Ramazanov A., C. Bazylhan

CONCEPTUAL BASIS OF HOSPITALITY.

Ramazanov A., Zh. Kuralov

ECONOMIC CHARACTERISTICS OF THE HOTEL BUSINESS

Torgaeva Sh.A

INTERNET MARKETING IN COMPANIES. 
Статистика, учет и аудит, $\mathbf{4 ( 8 4 ) 2 0 2 2}$ стр. $35-38$

ГРНТИ 06.51.02

УДК 338

https://doi.org/10.51579/1563-2415.2022-1.02

\title{
DEVELOP DIGITAL STORYTELLING INTEGRATES WITH ANIMATION AS AN INNOVATIVE INSTRUCTIONAL TOOL: EFFECTS ON STUDENT'S BE- HAVIOURAL ENGAGEMENT IN LEARNING
}

\author{
Tan Si Min \\ Master of Design, Lecturer Faculty of Art and Design, Southern University College, \\ Malaysia \\ e-mail: smtan@sc.edu.my
}

\begin{abstract}
From ancient times to today, storytelling has served popular instructional tool. Over the last decade, the emergence and availability of multimedia technologies, therefore upgrading the storytelling to digital storytelling. Today's students are growing up surrounded by digital technology. One form of multimedia that is becoming more popular in the education setting is digital storytelling. It is the best choice for teaching and learning nowadays. In line with this, animation has integrated with digital storytelling for the education system. Animation has notably contributed to provide the visualization system. Consequently, students prefer to learn from visual forms of subject content to engage them in learning more actively. Therefore, this paper discusses the student's behavioural engagement was foster by the digital storytelling integrates with animation.
\end{abstract}

Keywords: Digital Storytelling, Animation, Behavioural Engagement

Main provisions of the article. Implementing digital storytelling is an appropriate tool for learning and teaching, mainly student learning from multimedia technology to enhance their participation actively. Studies have proven that animation contributes to a positive outcome such as students are actively participating and engage, increase interest, and feel impressed.

Introduction. The innovation and advent of multimedia technology are developing rapidly in the 21 st century. It also has driven the evolution of the education system. Properly using information technology enables human development via educational activities [1]; [2]; [3]. Robin [4] stated that one of the most potent tools in multimedia technologies is digital storytelling. It has been suggested that with the use of digital storytelling in education. It is defined as a critical component of 21st-century learning technologies [5]. Digital storytelling can generate interest and attention among "digital generation" students in today's classroom [6]. There is a significant increase in the participation and engagement of the student in a positive way.

Nevertheless, having advanced digital storytelling alone without a proper visualization system does not promise that student can enhance their learning engagement [7]. Learning should be made more visual and interesting to foster student engagement. Nowadays, students are not merely digital generation and become mainly visual learners [8]; [9]. Animation has identified innovative multimedia technology that teachers should use in the classroom. As a multimedia technology, animation is at the forefront of the visualization [10]; [11]. A study by Pekdağ [12] argues that animation is the process of animating graphics in a specific sce- 


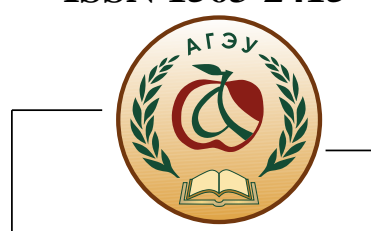

nario and is defined as an alternative teaching method to visualize knowledge. Therefore, it is essential to develop digital storytelling that integrates with animation to increase students' behavioural engagement.

\section{Literature Review}

Digital Storytelling. Constructivism is one of the most pivotal learning theories used and developed to enhance teaching and learning in recent times. Smeda et al. [13] pointed out that digital storytelling can facilitate a constructivist method for teaching and learning. Digital storytelling is a useful pedagogical approach that can improve the students' involvement in the learning process [14]. Digital storytelling is supported by a mixture of graphics, text, recorded audio narration, video, and music to present information on a specific topic through the use of multimedia technology [15]. It can be used to engage students in the content and make abstract or conceptual content more understanding.

Animation. The animation's usage is beneficial to students' learning. In various studies have proven that animation has been effectively delivering content to students. Specifically, animation is an interesting tool makes teaching methods and the classroom environment more engaging and entertaining as a whole. For instance, animation can help teachers to explain and reinforce the contents interestingly and entertainingly, particularly among digital generation [9]. Barak et al. [16] echoed that animation allow students to engage in three learning styles simultaneously, namely visual, auditory and kinesthetic which increases their knowledge comprehension.

Behavioural Engagement. Students engage in numerous different ways in the learning process. Behavioural engagement is active participation of students in learning. Behavioural engagement underpins that a particular set of behaviour such as learning behaviour [17]. Behavioural engagement refers to student's active engagement such as student pays attention, participate, listens and are involved in-class activities. Behaviours such as participation, effort, time on task may indicate the most robust engagement as students learn by performing such active action [18].

Conclusion. With the growing significance in fostering student participation in the educational sphere, behavioural engagement has become of particular interest for its role in persistence in learning and teaching. Hence, implementing digital storytelling is an appropriate tool for learning and teaching, mainly student learning from multimedia technology to enhance their participation actively. Studies have proven that animation contributes to a positive outcome such as students are actively participating and engage, increase interest, and feel impressed.

\section{References}

1 Pratama, H., Azman, M. N. A., Zakaria, N. A., Khairudin, M. (2021). Development of programmable logic controller teaching aids on electrical motor installation course among vocational school students in Aceh, Indonesia. Challenges of Science. Issue IV, pp. 117-127. https://doi.org/10.31643/2021.19

2 Kassymova, G. K., Vafazov, F. R., Pertiwi, F. D., Akhmetova, A. I., \& Begimbetova, G. A. (2021). Upgrading Quality of Learning with E-Learning System. Challenges of Science. Issue IV, 2021, pp. 26-34. https://doi.org/10.31643/2021.04

3 Pratama H, Azman MNA, Zakaria NA, Khairudin M. The effectiveness of the kit portable PLC on electrical motors course among vocational school students in Aceh, Indonesia. Kompleksnoe Ispol'zovanie Mineral'nogo Syr'a = Complex Use of Mineral Resources. 2022;320(1): 75-87. https://doi.org/10.31643/2022/6445.09 


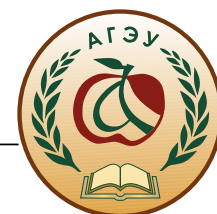

4 Robin, B. (2005). Educational uses of digital storytelling. Main directory for the educational uses of digital storytelling. Instructional Technology Program. University of Huston.

5 Brailas, A. (2017). Digital storytelling in the classroom: How to tell students to tell a story. International Journal of Teaching and Case Studies, 8(1), 16-28.

6 Robin, B. (2006, March). The educational uses of digital storytelling. In Society for Information Technology \& Teacher Education International Conference (pp. 709-716). Association for the Advancement of Computing in Education (AACE).

7 Phoon, G. C., Idris, M. Z., \& Rahina Nugrahani. (2021). Virtual Reality (VR) in 21st. Century Education: The Opportunities and Challenges of Digital Learning in Classroom. Asian Pendidikan, 1(2), 105-110. https://doi.org/10.53797/aspen.v1i2.15.2021

8 Roberto, I. J. (2010). Teaching \& Learning with the iGeneration. Children's Faith Formation, 45.

9 Chan, C. K. (2013). Use of animation in engaging teachers and students in assessment in Hong Kong higher education. Innovations in Education and Teaching International, 52(5), 474-484.

10 Tversky, B., Morrison, J. B., \& Betrancourt, M. (2002). Animation: Can it facilitate? International Journal of Human-Computer Studies, 57 (4), 247-262.

11 Xiao, L. (2013). Animation trends in education. International Journal of Information and Education Technology, 3(3), 286-289.

12 Pekdağ, B. (2010). Alternative methods in learning chemistry: Learning with animation, simulation, video and multimedia. Journal of Turkish Science Education, 7(2), 79110.

13 Smeda, N., Dakich, E., \& Sharda, N. (2014). The effectiveness of digital storytelling in the classrooms: a comprehensive study. Smart Learning Environments, 1(1), 1-21.

14 Md Nor, N. H., \& Mokhtar, Z. (2021). Penggunaan Aplikasi Karnaugh Map (KMap) Solver dalam Kursus Sistem Elektronik Digital. ANP Journal of Social Science and Humanities, 2(1), 73-79. https://doi.org/10.53797/anpjssh.v2i1.10.2021

15 Alismail, H. A. (2015). Integrate digital storytelling in education. Journal of Education and Practice, 6(9), 126-129.

16 Barak, A., Ashkar, T., \& Dori, Y. J. (2011). Learning science via animated movies: It effect on students' thinking and motivation. Computers \& Education, 56(3), 839-846.

17 Fredricks, J. A., Blumenfeld, P. C., \& Paris, A. H. (2004). School engagement: Potential of the concept, state of the evidence. Review of Educational Research, 74(1), 59-109.

18 Hospel, V., \& Galand, B. (2016). Are both classroom autonomy support and structure equally important for students' engagement? A multilevel analysis. Learning and Instruction, 41, 1-10.

\section{ЦИФРЛІК МІНЕЗ-ҚҰЛЫҚТЫ ДАМЫТУ ЖӘНЕ МУЛЬТИФИКАЦИЯ МЕН ИННОВАЦИЯЛЫҚ ОҚЫТУ ҚҰРАЛЫ РЕТІНДЕ ИНТЕГРАЦИЯЛАУ: ОҚУДАҒЫ СТУДЕНТТЕРДІН МІНЕЗ-ҚҰЛҚЫНА ӘСЕРІ}

\section{Тан Си Мин}

Дизайн магистрі, өнер және дизайн факультеті, Онтүстік университет колледжі, Малайзия e-mail:smtan@sc.edu.my

Түйін: Ерте заманнан күні бүгінге дейін дңзіме халықтық оқу құральы қыызметін атқ̧арып келеді. Соңъвы онжылдықта мультимедиялық технологияның пайда болуы 


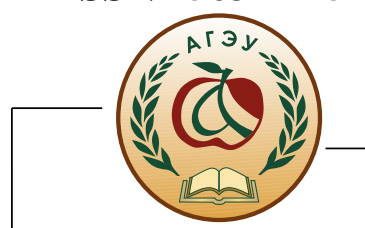

мен қолжетімділігі хикаяларды сандық дңзімелеуге дейін жаңуартуха әкелді. Қазіргі студенттер ичифрльқ ортада өсіп келеді. Білім беру ортасында танымал больп келе жатқан мультимедианың бір түрі - сандық дңгімелер. Бұл қ̧азіргі уақытта оқыту мен оку үшін ең жақ̧сы таңдау. Сәйкесінше, анимация білім беру жүйесінде ичифрлық дңгімелеумен біріктірілді. Анимация визуализация жүйесін құрува үлкен үлес қосты. Демек, студенттер оку прочесіне белсенді түрде құатыстыру үшін пән мазмұнының көрнекі формаларынан үйренуді жөн көреді. Осылайша, бұл мақалада анимациямен біріктірілген ициррльқ дңгімелеу арқылы жеңілдетілген студенттердің мінез-құльққ әрекеті талқыланады.

Түйінді сөздер: сандық әңъгіме, анимация, мінез-құльық өзара әрекеттесу.

\title{
РАЗРАБОТКА ЦИФРОВОГО ПОВЕДЕНИЯ И ИНТЕГРИРОВАНИЕ С МУЛЬТИФИКАЦИЕЙ В КАЧЕСТВЕ ИННОВАЦИОННОГО УЧЕБНОГО СРЕДСТВА: ВЛИЯНИЕ НА ПОВЕДЕНИЕ УЧАЩИХСЯ В ОБУЧЕНИИ
}

\author{
Тан Си Мин \\ Магистр дизайна, преподаватель факультета искусства и дизайна \\ Южного университетского колледжа, Малайзия \\ e-mail:smtan@sc.edu.my
}

\begin{abstract}
Аннотация: С древних времен и до наших дней повествование служило популярным учебным пособием. За последнее десятилетие появление и доступность мультимедийных технологий привели к обновлению повествования до ичифрового повествования. Современные студенты растут в окружении ичифровых технологий. Одной из форм мультимедиа, которая становится все более популярной в образовательной среде, является циирровое повествование. Это лучший выбор для преподавания и обучения в настоящее время. В соответствии с этим анимация интегрировалась с иифровым повествованием в системе образования. Анимация внесла значительный вклад в создание системь визуализачии. Следовательно, учащиеся предпочитают учиться на визуальных формах предметного содержания, чтобы активнее вовлекать их в процесс обучения. Таким образом, в этой статье обсуждается поведенческая вовлеченность учащихся, которой способствует изифровое повествование, интегрированное с анимацุией.
\end{abstract}

Ключевые слова: ичирровое повествование, анимачия, поведенческое взаимодействие.

Author information

Tan Si Min - Master of Design, Lecturer in Faculty of Art and Design, Southern University College, Malaysia, Email: smtan@sc.edu.my

Информация об авторе

Тан Си Мин - магистр дизайна, преподаватель факультета искусства и дизайна Южного университетского колледжа, Малайзия, электронная почта: smtan@sc.edu.my

Автор туральы ақпарат

Тан Си Мин - дизайн магистрі, өнер және дизайн факультетінің оқытушысы, Оңтүстік университет колледжі, Малайзия, Электрондық пошта: smtan@sc.edu.my 


\section{ПРАВИЛА ДЛЯ АВТОРОВ ЖУРНАЛА}

(с учетом изменений в Требованиях к научным изданиям для включения их в Перечень изданий, рекомендуемых для публикации результатов научной деятельности-Приказ Министра образования и науки Республики Казахстан от 30 апреля 2020 года № 170)

Журнал «Статистика, учет и аудит» (в дальнейшем - Журнал) публикует оригинальные работы ученых и специалистов научно-исследовательских организаций, высших учебных заведений, организаций и административных структур Казахстана, а также иностранных авторов. В журнале публикуются оригинальные статьи по научным направлениям статистики, учета и аудита, микро и макроэкономические вопросы международной и отечественной экономики, финансов, информатики и педагогики. Также публикуются рецензии, хроники научной жизни и др. материалы, имеющие отношение к деятельности Учредителя журнала.

Обязательными условиями для публикации являются:

1.Соответствие публикуемых научных статей (в том числе обзоров) заявленной цели и тематическому направлению журнала. Научная статья - изложение собственных выводов и промежуточных или окончательных результатов научного исследования, экспериментальной или аналитической деятельности, содержащее авторские разработки, выводы, рекомендаций ранее не опубликованные и обладающие новизной; или посвященное рассмотрению ранее опубликованных научных статей, связанных общей темой (систематический обзор).

2.Структура научной статьи включает название, аннотацию, ключевые слова, основные положения, введение, материаль и методы, результаты, обсуждение, заключение, информацию о финансировании (при наличии), список литературы. В каждой оригинальной статье (за исключением социально-гуманитарного направления) обеспечивается воспроизводимость результатов исследования, описывается методология исследования с указанием происхождения оборудования и материалов, методов статистической обработки данных и других способов обеспечения воспроизводимости. Содержание других типов публикаций не превышает 10\% (десять) от общего количества статей в номере. При этом автор или коллектив авторов вносят значительный вклад в концепцию, научный дизайн, исполнение или интерпретацию заявленного научного исследования и создание научной статьи. Наличие библиографической информации - заголовка статьи, аннотации, ключевых слов, информации об авторах на английском языке обязательно.

2.1 В аннотации (аңдатпа, abstract) публикуемой статьи на языке статьи излагаются суть и использованные методы исследования, суммируются наиболее важные результаты и их значимость. Объем аннотации составляет не более 300 слов (минимальный объем-100 слов). 


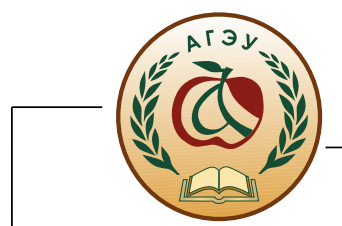

2.2 Резюме (түйін, summary) на двух не на языке статьи (казахском, русском и английском) языках. Например, резюме и summary- это не переводы аңдатпа, а краткое изложение о статье на русском и английском языках (если статья написана на казахском) и рекомендуется их приводить после списка литературы.

2.3 Ключевые слова (түйінді сөздер, key words) предназначены для поиска текста статьи и определения ее предметной области. Например, они приводятся после аннотации (если статья написана на русском) и двух резюме (түйін, summary). Ключевые слова должны обеспечить наиболее полное раскрытие содержания статьи.

2.4 Информация об авторах - имена (Фамилия И.О. авторов), аффилиации (полное название учреждения, которое представляет автор (авторы), название страны, и адреса всех авторов публикаций, в том числе с указанием основного автора-выделить звездочкой (*), е-таil (основного автора).

3. Список литературы. Ссылки на источники в тексте статьи даются только в квадратных скобках (без цитирования [12], при цитировании или пересказе авторского текста [12, с. 29]). Используемая литература, указываемая в ссылках, дается в конце статьи пронумерованной и в порядке упоминания по авторам. Архивные материалы в список не включаются, ссылки на них помещаются в тексте в круглых скобках. При использовании в статье: источников законодательных, нормативно-правовых актовссылки на них делать в тексте сразу же после них, а источников из электронных ресурсов или удаленного доступа (Интернета) в списке литературы приводится библиографическая запись источника и ссылка на сетевой ресурс с полным сетевым адресом в Интернете. Желательно указывать дату обращения к ресурсу. Список литературы предоставляется на языке оригинала и должен состоять не более чем из 20 наименований.

3.1 Наличие транслитерированных списков литературы (используемых источников) к каждой статье. Существуют различные системы транслитераций. Предложение редакции по транслитерации (вы имеете право найти другой способ):

3.1. На данной странице Вы можете выполнить транслит - онлайн русских букв латиницей:

Транслитерация с русского на английский онлайн

https://lim-english.com/posts/transliteratsiya-s-russkogo-na-angliiskij/

4. Ответственность за содержание статей несут авторы.

5. Этические принципы, которыми должен руководствоваться автор научной публикации. Представление статьи на рассмотрение в редакцию подразумевает, что она содержит полученные автором (коллективом авторов) новые научные результаты, которые ранее нигде не публиковались. Автор должен осознавать, что несет персональную ответственность за представляемый текст рукописи. Это предполагает соблюдение следующих принципов:

5.1. Автор статьи гарантирует, что предоставляет редакции журнала достоверные результаты выполненной научной работы или исследования. Заведомо ложные или 
сфальсифицированные утверждения приравниваются к неэтичному поведению и являются неприемлемыми.

5.2. В случае, если главный редактор журнала запрашивает у автора научной статьи ее исходные данные для рецензирования, автор, если это возможно, должен быть готов предоставить открытый доступ к таким данным; автор также берет на себя обязательство сохранять исходные материалы статьи в течение разумного периода, прошедшего после ее публикации.

5.3. Автор гарантирует, что результаты исследования, изложенные в рукописи, представляют собой самостоятельную и оригинальную работу. В случае использования фрагментов чужих работ или заимствования утверждений других авторов, в статье должны быть оформлены соответствующие библиографические ссылки с обязательным указанием автора и первоисточника. Все статьи проходят обязательную проверку через систему «Антиплагиат». Все статьи проверяются на предмет обнаружения плагиата (оригинальность должна быть не менее 70\%). Применяется лицензионная программа АНТИПЛАГИАТ.ВУЗ Договор № 1065 от 29 декабря 2020 г.) Чрезмерные заимствования, а также плагиат в любых формах, включая неоформленные цитаты, перефразирование или присвоение прав на результаты чужих исследований, являются неэтичными и неприемлемыми действиями. Статьи, представляющие собой компиляции из материалов, ранее опубликованных другими авторами, без их творческой переработки и собственного авторского осмысления, редакцией журнала к публикации не принимаются.

5.4. Автор безусловно признает вклад всех лиц, так или иначе повлиявших на ход исследования или определивших характер представленной научной работы. В частности, в статье должны быть сделаны библиографические ссылки на отечественные и зарубежные публикации, которые имели значение при проведении исследования. Информация, полученная в частном порядке путем разговора, переписки или обсуждения с третьими лицами, не должна использоваться без получения открытого письменного разрешения от ее источника. Все источники должны быть раскрыты. Даже в том случае, если используемые в статье письменные или иллюстративные материалы получены от большого числа людей, автору статьи необходимо представить в редакцию все соответствующие разрешения на использование этих материалов.

5.5. Автор гарантирует, что представленная в журнал рукопись статьи не находится на рассмотрении редакции другого научного журнала и не была ранее опубликована в другом журнале. Несоблюдение этого принципа расценивается как грубое нарушение этики публикаций и дает основание для снятия статьи с рецензирования. Текст статьи должен быть оригинальным, то есть публиковаться в представленном виде в периодическом печатном издании впервые. Если элементы рукописи ранее были опубликованы в другой статье, автор обязан сослаться на более раннюю работу и указать, в чем состоит существенное отличие новой работы от предыдущей. Дословное копирование собственных работ и их перефразирование неприемлемы, они могут быть использованы только как основа для новых выводов. 


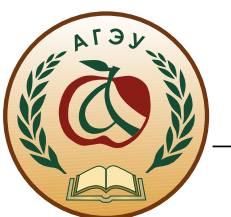

5.6. Автор статьи гарантирует правильность списка соавторов. В числе соавторов должны быть указаны все лица, внесшие существенный интеллектуальный вклад в концепцию, структуру, а также в проведение или интерпретацию результатов представленной работы. Другим лицам, чье участие в представленной в журнал работе ограничилось некоторыми ее аспектами, должна быть выражена благодарность. Автор статьи должен также гарантировать, что все соавторы ознакомлены с окончательным вариантом статьи, одобрили его и согласны с ее представлением к публикации. Все указанные в статье соавторы несут совокупную ответственность за ее содержание. Если статья является мультидисциплинарной работой, соавторы могут также принимать на себя ответственность за свой личный вклад в работу, продолжая при этом нести коллективную ответственность за результат исследования в целом. Недопустимо указание в качестве соавторов статьи лиц, не принимавших участия в исследовании.

5.7. В случае обнаружения существенных ошибок или неточностей в статье на этапе ее рассмотрения или после ее опубликования автор обязан незамедлительно уведомить об этом редакцию журнала и принять совместное решение о признании ошибки и/или ее исправлении в максимально короткие сроки. Если редакция узнает от третьего лица, что опубликованная работа содержит существенные ошибки, автор обязан незамедлительно исправить их либо предоставить редакции доказательства правильности ранее предоставленной им информации.

5.8. Автор обязуется указывать в своих рукописях все источники финансирования работы, заявлять о возможных конфликтах интересов, которые могут повлиять на результаты исследования, их интерпретацию, а также на суждения рецензентов. Потенциальные конфликты интересов должны быть раскрыты как можно раньше.

6. Поступившие от авторов научные статьи проходят первичный контроль на комплектность и правильность оформления. Далее статья направляется на предмет обнаружения плагиата (оригинальность должна быть не менее 70\%). Применяется лицензионная программа АНТИПЛАГИАТ.ВУЗ Договор № 1065 от 29 декабря 2020 г.), после чего, научные статьи, поступившие в редакцию, проходят обязательное слепое рецензирование порядок прохождения, которых описан в разделе Рецензирование.

При отрицательном отзыве рецензентов редакция Журнала обязуется сообщать авторам все комментарии об их работе, сделанные рецензентами, если только они не содержат обидные или клеветнические замечания.

7. В конце статьи предоставляются заполненные формы для размещения сборника статей в Научной электронной библиотеке (eLibrary.ru) и включения сборника статей в Российский индекс научного цитирования (РИНЦ):

\section{ФОРМА}

для размещения сборника статей в Научной электронной библиотеке (eLibrary.ru) и включения сборника статей в Российский индекс научного цитирования (РИНЦ)

1. Название статьи: на казахском, русском и английском языках 
2. Сведения об авторе (авторах):

- фамилия, имя, отчество (полностью) автора (авторов) с указанием ученой степени и ученого звания (при наличии) на трех языках:

- место работы автора (авторов) (должность и организация) на трех языках:

- контактная информация:

e-mail автора (авторов) - тел.номер автора (авторов) -

8. Редакция оставляет за собой право редакторской правки.

Технические требования

1. Общий объем статьи, включая аннотацию, ключевые слова, литературу, таблицы и рисунки не должен превышать 6-8 страниц. Исключение составляют заказные и обзорные статьи.

2. Статьи должны быть оформлены в строгом соответствии шрифтом гарнитуры Times New Roman.

МРНТИ

\section{Схематический пример оформления статьи}

УДК 339.74

DOI (Digital Object Identifier) xxxxxxxxxx

По центру приводятся: Название статьи

(Поля: сверху - 2 см., слева-3 см., справа -1,5 см. Шрифт полужирный. Кегль-14 пт, межстрочный интервал - одинарный.)

Фамилии и инициалы авторов (напр.И.В.Иванов, Ю.П.Крылов)

Полное название учреждения, которое представляе(ю)т автор(ы) с указанием города и страны, электронного адреса основного автора выделением надстрочной звездочкой. Если авторы из разных учреждений, то соответствие между автором и учреждением устанавливается надстрочными индексами, например:

\section{${ }^{*}$ И.В. Иванов ${ }^{1}$, Ю.П. Крылов ${ }^{2}$}

${ }^{1}$ Алматинский гуманитарно-экономический университет, Алматы, Казахстан 2 Международная академия бизнеса, Алматы, Казахстан e-mail: ivanov@mail.ru

- Аннотация.

- Ключевые слова.

- Текст статьи: Поля: сверху, снизу - 2 см., слева - 3 см., справа -1,5 см. Шрифт Times New Roman. Кегль-14 пт. Абзацный отступ-1,25 см., межстрочный интервал одинарный).

- Список литературы. Транслитерированный список литературы (References)

- После списка литературы приводятся:

Название статьи перед каждым резюме на двух не на языке статьи (казахском, русском и английском) языках. 
ISSN 1563-2415

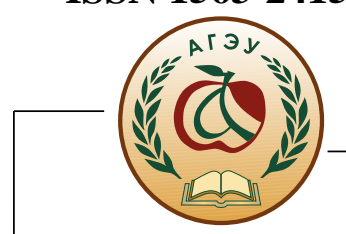

После каждого названия статьи приводятся см. выше (последовательно) пп. 2.4, 2.2, 2.3 Руководства для авторов

3. Таблицы и рисунки с названиями должны быть пронумерованы по порядку (если их несколько). Нумерация таблицы (Таблица 1.) должна быть расположена вверху слева выше названия таблицы через абзацный отступ.

4. Рисунки, фотографии, таблицы должны быть четкими и контрастнымив формате jpg, иметь разрешение не менее 300 dpi, подрисуночные надписи к ним должны быть расположены ниже рисунка по центру. Цветные рисунки, диаграммы не допускаются.

5. На рисунках должен быть минимум буквенных и цифровых обозначений, обязательно объясненных в статье или подрисуночных подписях.

6. Необъясненные сокращения слов, имен, названий, кроме общепринятых, не допускаются. Аббревиатуры расшифровываются после первого появления в тексте, например: Организация по экономическому сотрудничеству и развитию (ОЭСР).

7. Упомянутые в статьях единицы измерения должны соответствовать Международной системе единиц СИ.

8. Математические формулы должны быть набраны в Microsoft Education (каждая формула - один объект). Нумеровать следует лишь те формулы, на которые имеются ссылки.

9. Редакция не занимается литературной и стилистической обработкой статей. Материалы, статьи не возвращаются

10. Авторам для рассмотрения статьи необходимо представить рукопись на сайт www.sua.aesa.kz, и копию статьи со всеми сопроводительными документами согласно требованию направить на e-mail: zhurnal.aesa.99@ mail.ru :

10.1. Электронную версию статьи;

10.2.Наукометрическую базу данных для РИНЦ

10.3. Представить сканированную копию квитанцию об оплате за публикацию статьи и квитанцию об оплате за присвоение DOI (Digital Object Identifier) авторам, (только после подтверждения редакцией Журнала статьи к опубликованию).

ВНИМАНИЕ: DОI (Digital Object Identifier) присваивается регистрационным агентством International DOI Foundation (Интернэйщенел ДОИ Фаундэйщен). 